\title{
Gonadal Hormones Affect Spine Synaptic Density in the CA1 Hippocampal Subfield of Male Rats
}

\author{
Csaba Leranth, ${ }^{1,2}$ Ors Petnehazy, ${ }^{1}$ and Neil J. MacLusky ${ }^{3}$ \\ Departments of ${ }^{1}$ Obstetrics and Gynecology and ${ }^{2}$ Neurobiology, Yale University School of Medicine, New Haven, Connecticut 06520 , and ${ }^{3}$ Center for \\ Reproductive Sciences, Columbia University Medical School, New York, New York 10032
}

\begin{abstract}
The effects of androgen on the density of spine synapses on pyramidal neurons in the CA1 area of the hippocampus were studied in male rats. Gonadectomy (GDNX) had no significant effect on the number of CA1 pyramidal cells but reduced CA1 spine synapse density by almost $50 \%$ (to $0.468 \pm 0.018$ spine synapses $/ \mu \mathrm{m}^{3}$ ) compared with sham-operated controls $\left(0.917 \pm 0.06\right.$ spine synapses $\left./ \mu \mathrm{m}^{3}\right)$. Treatment of GDNX rats with testosterone propionate $(500 \mu \mathrm{g} / \mathrm{d}$, s.c., $2 \mathrm{~d})$ increased spine synapse density to levels (1.01 \pm 0.026 spine synapses $\left./ \mu \mathrm{m}^{3}\right)$ comparable with intact males. A similar increase in synapse density $\left(1.013 \pm 0.05\right.$ spine synapses/ $\left.\mu \mathrm{m}^{3}\right)$ was observed in GDNX animals after treatment with dihydrotestosterone (DHT) $(500 \mu \mathrm{g} / \mathrm{d}$, s.c., $2 \mathrm{~d}$ ) but not after estradiol (10 $\mu \mathrm{g} / \mathrm{d}$, s.c., $2 \mathrm{~d}$; $0.455 \pm 0.02$ spine synapse $\left./ \mu \mathrm{m}^{3}\right)$. These data indicate that testosterone is important for maintenance of normal spine synapse density in the CA1 region of the male rat hippocampus. The comparable responses to testosterone and the non-aromatizable androgen DHT, coupled with the lack of response to estradiol, suggest that testosterone acts directly on hippocampal androgen receptors rather than indirectly via local estrogen biosynthesis.
\end{abstract}

Keywords: testosterone; dihydrotestosterone; estrogen; spine synapse density; CA1 hippocampal area; unbiased stereological calculation

\section{Introduction}

Previous studies have demonstrated that, during the female reproductive cycle, physiological levels of gonadal steroids greatly influence the density of pyramidal cell dendritic spines and spine synapses in the CA1 subfield of the hippocampus (Gould et al., 1990; Woolley et al., 1990; Woolley and McEwen, 1992; Leranth et al., 2000, 2002). In ovariectomized (OVX) rats, intact subcortical connections to the hippocampus are required for estrogeninduced increases in spine synapse density (Leranth et al., 2000), whereas local administration of estradiol (E) into the supramammillary area mimics the effects of systemic E administration (Leranth and Shanabrough, 2001), suggesting that the effects of E on CA1 pyramidal cells are at least partly indirect.

The male rat hippocampus is rich in androgen receptorexpressing cells (Simerly et al., 1990; Brown et al., 1995), indicating that it is a target for testosterone (T) action. In the CA1 area, the androgen receptors appear to be primarily located in pyramidal neurons (Clancy et al., 1992; Kerr et al., 1995). The rat hippocampus also contains low levels of aromatase (MacLusky et al., 1994), the enzyme converting T to E. Thus, effects of circulating $T$ could be mediated either via actions of the steroid on androgen receptors or conversion to E. Morphological studies suggests that androgens and estrogens both modulate hippocampal structure in the male. In the CA1 area, spine density peaks at puberty in

\footnotetext{
Received 0ct. 9, 2002; revised Dec. 18, 2002; accepted Dec. 18, 2002.

This work was supported by National Institutes of Health Grants MH60858 and NS42644 (C.L.).

Correspondence should be addressed to Dr. (saba Leranth, Department of Obstetrics and Gynecology, Yale University School of Medicine, 333 Cedar Street, Farnam Memorial Building 313, New Haven, CT 06520-8063. E-mail: csaba.leranth@yale.edu.

Copyright $\odot 2003$ Society for Neuroscience $\quad$ 0270-6474/03/231588-05\$15.00/0
}

male mice, and this increase can be prevented by prepubertal castration (Meyer et al., 1978). Orchidectomy reduces the density of CA1 area pyramidal cell spines in male rats, an effect that is partially reversed by E administration (Lewis et al., 1995). These previous studies, however, used techniques (light microscopic examination of Golgi-impregnated material) that do not provide information about synaptic connectivity.

The hippocampus is sexually differentiated as a result of developmental androgen exposure in the male (Roof and Havens, 1992; Lewis et al., 1995; Isgor and Sengelaub, 1998). In females, the E-induced increase in spine synapse density in OVX rats is associated with augmented CA1 long-term potentiation (LTP) (Cordoba Montoya and Carrer, 1997), whereas T administration to castrated, adult males has been reported to have an opposite, negative effect on CA1 LTP (Harley et al., 2000). A possible interpretation of these findings might be that the effects of $\mathrm{E}$ on the hippocampus of the male are different from those of the female. Alternatively, it is possible that the effects of $\mathrm{T}$ might involve contributions from both androgen and estrogen receptormediated events, resulting in different morphological consequences after exposure to $\mathrm{T}$ or $\mathrm{E}$.

The aim of this study, therefore, was to determine the effects of $\mathrm{T}$ and $\mathrm{E}$ on the density of spine synapses on CA1 area pyramidal cells in gonadectomized male rats. Our data suggest that, in the male, T has a dramatic impact on CA1 spine synapse density but that this effect is mediated primarily via androgen rather than estrogen receptors.

\section{Materials and Methods}

Animals. Male Sprague Dawley (280-300 gm; Charles River Laboratories, Wilmington, MA) rats were used in this study. Animals were kept 
under standard laboratory conditions, with tap water and regular rat chow available ad libitum, in a $12 \mathrm{hr}$ light/dark cycle. Experiments conformed to Yale University and international guidelines on the ethical use of animals, and experimental protocols were approved by the Institutional Animal Care and Use Committee of Yale University Medical School.

Surgery and hormonal manipulations. Rats were deeply anesthetized using a ketamine-xylazine mixture $(3 \mathrm{ml} / \mathrm{kg}$, i.m.; containing $25 \mathrm{mg}$ of ketamine, $1.2 \mathrm{mg}$ of xylazine, and $0.03 \mathrm{mg}$ of acepromazine in $1 \mathrm{ml}$ of saline) and gonadectomized (GDNX). One week later, four rats received testosterone propionate (TP), four rats received dihydrotestosterone (DHT), and four rats received estradiol benzoate treatment. Treatments consisted of two subcutaneous injections separated by $24 \mathrm{hr}$ of $500 \mu \mathrm{g}$ of $\mathrm{TP}, 500 \mu \mathrm{g}$ of DHT, or $10 \mu \mathrm{g}$ of E (in $100 \mu \mathrm{l}$ of sesame oil), respectively. The control animals $(n=4)$ were sham operated and received only sesame oil injections. Rats were kept in individual cages.

Tissue processing. Two days after the second hormone injection, rats were killed under deep ether anesthesia by transcardial perfusion of heparinized saline, followed by a fixative containing $4 \%$ paraformaldehyde and $1 \%$ glutaraldehyde in $0.1 \mathrm{~m}$ phosphate buffer, $\mathrm{pH}$ 7.35. Brains were removed and postfixed for $2 \mathrm{hr}$ in the same fixative. The hippocampi were dissected out, and vibratome sections $(100 \mu \mathrm{m})$ were cut perpendicular to the longitudinal axis of the hippocampus. Sections were postfixed in $1 \%$ osmium tetroxide (30 min), dehydrated in ethanol (the $70 \%$ ethanol contained $1 \%$ uranyl acetate for $30 \mathrm{~min}$ ), and flat embedded in Araldite.

Synapse counts. The spine synapse density was calculated according to our standard protocol using unbiased stereological methods (Leranth et al., 2000, 2002; Leranth and Shanabrough, 2001). Briefly, first to assess possible changes in the volume of the tissue, a correction factor was calculated assuming that the brief hormonal treatments do not alter the total number of pyramidal cells (Rusakov et al., 1997). Thus, in all hippocampi, six to seven disector pairs (pairs of adjacent $2 \mu \mathrm{m}$ toluidine blue-stained semithin sections mounted on slides) were analyzed using the technique of Braendgaar and Gundersen (1986). The pyramidal cell density value $(D)$ was calculated using the formula $D=N / s T$, where $N$ is the mean disector score across all of the sampling windows, $T$ is the thickness of the sections $(2 \mu \mathrm{m})$, and $s$ stands for the length of the window. On the basis of these values, a dimensionless volume correction factor $k_{v}$ was introduced: $k_{v}=D / D_{1}$, where $D_{1}$ is the main density across the groups of hippocampi. Thereafter, pairs of consecutive serial ultrathin sections ("reference" and "look-up" sections) were cut from the vibratome sections (representing all areas of the hippocampus along its longitudinal axis) from an area located between the upper and middle third of the CA1 stratum radiatum (3-500 $\mu \mathrm{m}$ from the pyramidal cell layer) and collected on Formvar-coated single-slot grids. Digitized images were made at a magnification of $11,000 \times$ in a Tecnai 12 electron microscope furnished with an AMT Advantage 4.00 HR/HR-B CCD camera system connected to a computer via a PCI-Bus frame grabber board (Advanced Microscopy Techniques, Danvers, MA) with the observer blinded to the experimental treatment. Areas occupied by potentially interfering structures, such as blood vessels, large dendrites, or glial cells, were subtracted from the areas measured using the NIH Scion Image processing software. To obtain a comparable measure of synaptic numbers, unbiased for possible changes in synaptic size, the disector technique was used (Sterio, 1984). Thus, the density of spine synapses of pyramidal cell dendrites was calculated with the help of a reference grid superimposed on the EM prints. The disector volume (volume of reference) was the unit area of the reference grid multiplied by the distance between the upper faces of the reference and look-up sections (Braendgaar and Gundersen, 1986). Only those spine synapses were counted that were present on the reference section but not on the look-up section (Fig. 1). To increase the efficiency of spine synapse counting, the analysis was performed treating each reference section as a look-up section and vice versa (Woolley and McEwen, 1992). Section thickness (average of $0.075 \mu \mathrm{m}$ ) was determined by using the electron scattering technique (Small, 1968). The measured synaptic density values were divided by the volume correction factor $k_{v}$. This correction provided a synaptic density estimate normalized with respect to the density
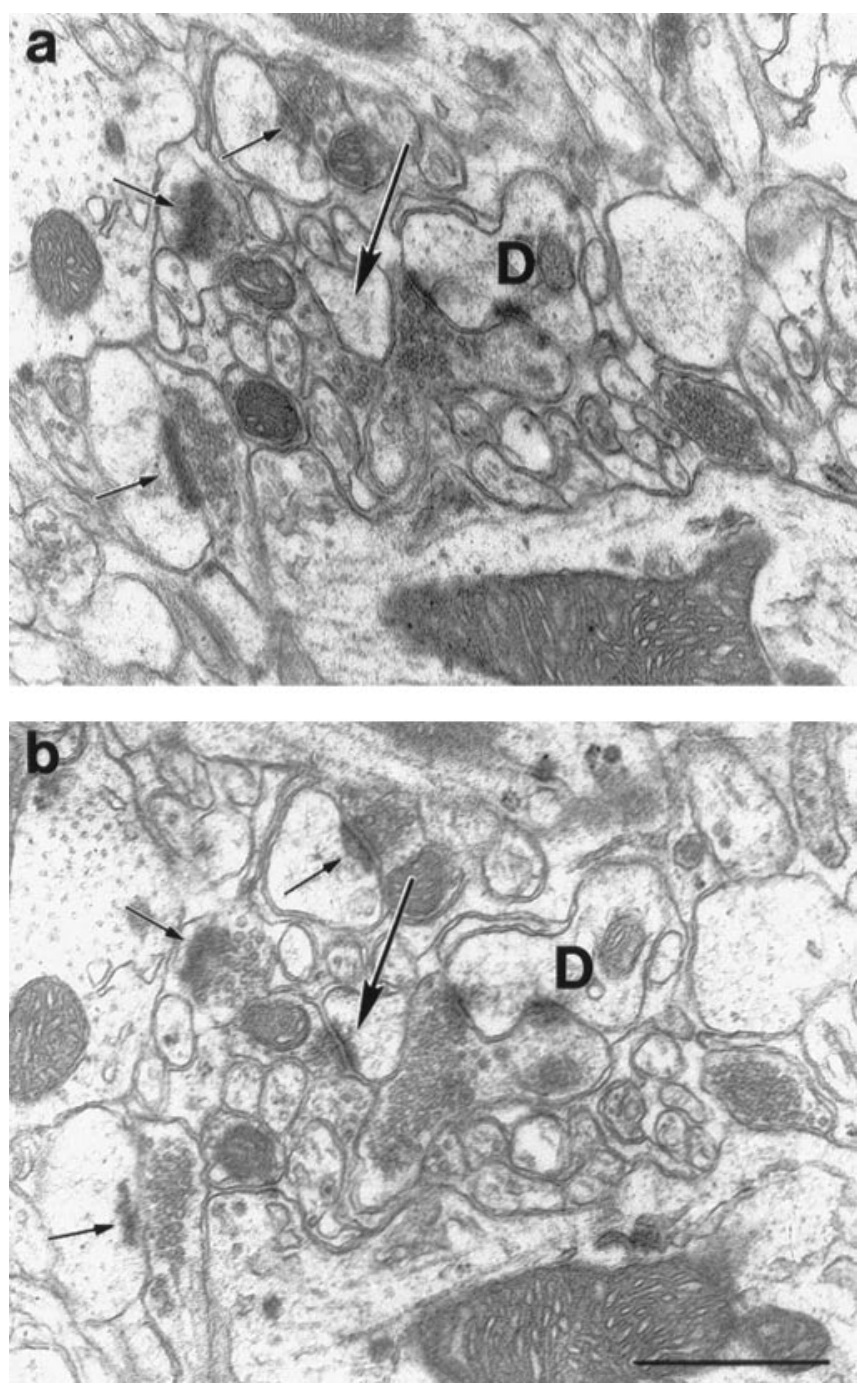

Figure 1. Electron micrographs demonstrate identical areas on two consecutive, serial sections taken from the stratum radiatum of the $C A 1$ subfield. $a$ shows the reference section and $b$ the look-up section. Only those spine synapses were counted that were seen just in one section. Long arrows point at the same spine, which forms synaptic contact only in $b$. Spine synapses that are in postsynaptic position in both sections (small arrows) and axo-dendritic synapses were not counted. D, Dendrite. Scale bar, $1 \mu \mathrm{m}$.

of pyramidal cells and also accounted for possible changes in hippocampal volume.

Statistical analysis. At least five neuropil fields were photographed on each electron microscopic grid. With at least eight grids from each vibratome section (containing a minimum of two pairs of consecutive, serial ultrathin sections), each animal provided a minimum of $5 \times 8 \times$ $2=80$ or more neuropil fields. The means and SEs were calculated. Means were compared using pairwise $t$ tests (two-tailed probabilities) among groups, as well as using the noncentral $F$ statistic to test the difference in the ratios of means between groups. A level of confidence of $p<0.05$ in two-tailed tests was adopted.

\section{Results}

No significant differences were observed between the density values of CA1 pyramidal cells of rats that were GDNX and received different hormone treatments and control animals (control, $1780 \pm 193$ cells $/ \mathrm{mm}^{2}$; TP plus GDNX, $1716 \pm 168 \mathrm{cells} / \mathrm{mm}^{2}$; DHT plus GDNX, $1702 \pm 185$ cells $/ \mathrm{mm}^{2}$; E plus GDNX, $1750 \pm$ 175 cells $/ \mathrm{mm}^{2}$ ).

In the electron microscope, no obvious qualitative differences 


\section{Spine Synapse Density in the CA1 Hippocampal Subfield of Male Rats}

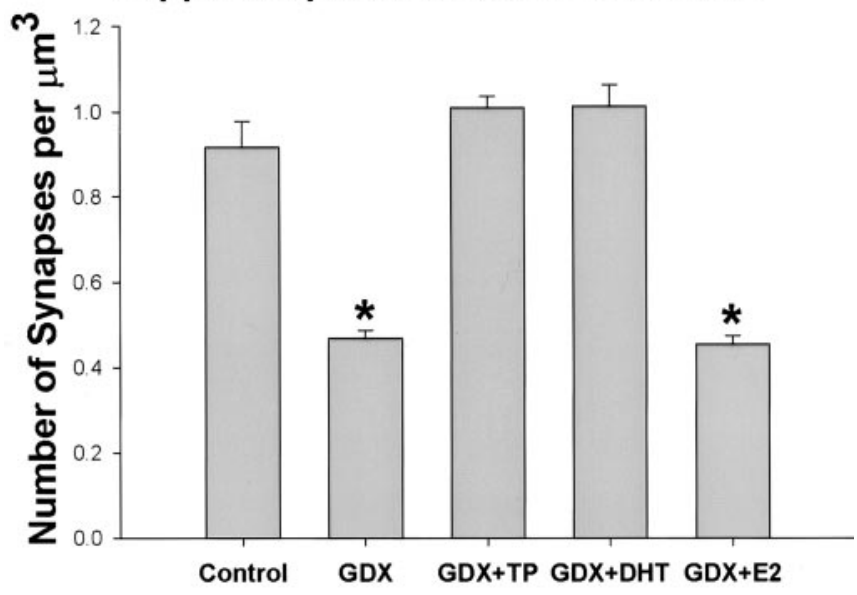

Figure 2. Bar graph shows the result of the unbiased stereological calculation of spine synapse density in the stratum radiatum of the CA1 subfield of control, gonadectomized (GDX), gonadectomized plus testosterone-treated $(G D X+T)$, gonadectomized plus dihydrotesteronetreated $(G D X+D H T)$, and gonadectomized plus estrogen-treated $(G D X+E 2)$ male rats. There is no significant difference between the density values of spine synapses between the Control, $G D X+T$, and $G D X+D H T$ animals. However, the spine synapse density of the $G D X$ and $G D X+E 2$ rats is significantly $(p<0.001)$ lower $(48 \%)$ than that of control animals.

could be observed by comparing the ultrastructure of the CA1 stratum radiatum of control rats and animals that received different hormonal treatments. In contrast, the results of the unbiased statistical analyses provided evidence of different effects of the various hormone treatments on the density of spine synapses in this region (Fig. 2). The highest density of CA1 area pyramidal cell spine synapses was calculated in the gonadectomized and TPor DHT-treated rats. A slightly, but not significantly, lower synaptic density was observed in the sham-gonadectomized control group. Significantly lower $(\sim 50 \%)$ spine synapse densities were observed in the GDNX- and GDNX plus estrogen-treated rats (Fig. 2).

\section{Discussion}

These observations demonstrate that, in adult male rats, the integrity of CA1 area pyramidal cell spine synapses depends on the presence of circulating testosterone. GDNX dramatically reduces the number of spine synapses, a response that is reversed by treatment with either $\mathrm{T}$ or the non-aromatizable androgen DHT. In contrast, E administration has no significant effect on the spine CA1 synapse density in GDNX animals.

These data indicate a striking sexual dimorphism in the response mechanisms that maintain normal hippocampal CA1 structure. In the female, estrogen is a potent modulator of CA1 spine synapse density (Gould et al., 1990; Woolley et al., 1990; Woolley and McEwen, 1992; Leranth et al., 2000, 2002). In the male, however, the present data indicate that the dramatic loss of hippocampal CA1 spine synapse density after GDNX is not significantly affected by short-term E treatment. In contrast, treatment with T or DHT completely reverses the post-orchidectomy decline in hippocampal spine synapse numbers. The lack of effect of estrogen administration and the comparable responses observed with $\mathrm{T}$ and DHT strongly suggest that the effect of $\mathrm{T}$ is mediated via androgen receptors rather than by conversion of the androgen to estrogen. Different doses of $\mathrm{E}$ and the two androgens were used to reflect the fact that androgens normally circulate in the bloodstream at much higher levels than E, whereas only a small proportion of circulating $\mathrm{T}$ is normally aromatized and concentrated in the rat brain (Lieberburg and McEwen, 1977). The comparable response to $\mathrm{T}$ and DHT is consistent with the view that relatively little conversion of $\mathrm{T}$ to $\mathrm{E}$ occurs in the adult rat hippocampus (Lieberburg and McEwen, 1977; MacLusky et al., 1994). The apparent lack of response to systemic E administration is somewhat unexpected, in view of previous data indicating effects of $E$ treatment on dendritic structure in males, particularly because the doses of E used in this previous study (Lewis et al., 1995) were identical to those used here. In this previous study, however, the effects of $\mathrm{E}$ treatment on dendritic spine density, although statistically significant, were quantitatively much smaller than the effect of GDNX. Thus, spine density on the primary apical dendrites of CA1 pyramidal neurons was reduced by almost 50\% after GDNX (Lewis et al., 1995), a response consistent with the almost $50 \%$ decrease in the number of spine synapses observed in the present study. In contrast, E treatment induced only an $\sim 10 \%$ increase in dendritic spine density (Lewis et al., 1995) and no significant change in the number of spine synapses per cubic micrometer (Fig. 2).

Although the difference between the effects of DHT and E clearly suggests that estrogen receptors do not mediate the synaptic response to $\mathrm{T}$, this does not prove that $\mathrm{T}$ acts solely via the hippocampal intranuclear androgen receptor system. There may also be contributions from direct modulation of neurotransmitter receptor function. For example, T and DHT are both converted to $5 \alpha$-androstan $3 \alpha 17 \beta$ diol, which has been reported to have significant modulatory effects on $\mathrm{GABA}_{\mathrm{A}}$ receptors. This route of metabolism has been implicated in the behavioral effects of circulating androgens (Bitran et al., 1996; Frye and Reed, 1998; Frye et al., 2001).

Previous studies have demonstrated that androgens have powerful neuroprotective and homeostatic effects in the hippocampus (Sakata et al., 2000; Azcoitia et al., 2001; Pike, 2001; Shors et al., 2001). In several species, the hippocampus is sexually differentiated, at least in part because of androgen action in the male (Meyer et al., 1978; Lewis et al., 1995; Tabibnia et al., 1999). A significant positive effect of testosterone on hippocampal volume has been reported in meadow voles (Galea et al., 1999). Hippocampal CA1 spine density has been reported to be higher in females at proestrus than in males and to respond to stress in different directions in males and cycling females (Shors et al., 2001). A developmental component to sex differences in hippocampal structure is also suggested by studies demonstrating positive effects of perinatal androgen exposure in rats on CA1, CA3, and dentate gyrus cell densities (Roof and Havens, 1992; Isgor and Sengelaub, 1998). These long-term, differentiating effects of early androgen differ, however, from the more rapid, activational effects reported here: GDNX results within $10 \mathrm{~d}$ in an $\sim 50 \%$ loss of CA1 spine synapse density, an effect that is completely reversed within $3 \mathrm{~d}$ of instituting $\mathrm{T}$ or DHT replacement therapy (Fig. 2).

Numerous reports in the literature suggest that $\mathrm{T}$ has effects on neuroendocrine, neurophysiological, and behavioral responses involving the hippocampus. Patchev and Almeida (1996) have reported that hippocampal mineralocorticoid receptor (MR) and glucocorticoid receptor (GR) mRNA expression is regulated by gonadal steroids in adrenalectomized rats, in a sexspecific manner. Thus, hippocampal MR expression was significantly downregulated by E only in females, whereas E-induced changes in GR expression were observed only in males. In contrast, DHT significantly downregulated hippocampal MR ex- 
pression in both sexes (Patchev and Almeida, 1996). The effects of androgens and $\mathrm{E}$ on GR and MR regulation may contribute to the reported effects of these steroids on the neuroendocrine control of ACTH secretion. GDNX enhances the ACTH response to stress (Handa et al., 1994). Administration of E further augments stress-induced ACTH secretion in GDNX animals, whereas T or DHT return post-stress ACTH to levels comparable with those observed in intact rats (Handa et al., 1994). Sexual dimorphisms in the electrophysiological properties of the hippocampus also involve acute, activational effects of gonadal steroids (Foy et al., 1984). Smith et al. (2002) have reported recently that, after stimulation via the Schaeffer collaterals, hippocampal slices from intact male rats exhibit larger EPSP amplitudes recorded in CA1 than slices from either females or GDNX males. In vitro application of T significantly increased EPSP amplitudes in both sexes (Smith et al., 2002). The effects of androgen on hippocampal LTP are mixed and appear to depend on the experimental model. Using urethane-anesthetized male rats stimulated via the Schaeffer collaterals, Harley et al. (2000) reported that orchidectomized male rats show a significantly greater magnitude and duration of potentiation than rats replaced with T or DHT. In male mice, in contrast, Sakata et al. (2000) reported that, whereas LTP in CA1 pyramidal neurons evoked by high-frequency stimulation via commissural afferents is unaffected by gonadal status, LTP evoked by primed burst stimulation is attenuated by castration and restored to control levels by testosterone treatment. In this respect, the effects of $\mathrm{T}$ superficially resemble those of $\mathrm{E}$, which has also been shown to increase hippocampal excitability (Wong and Moss, 1992; Woolley et al., 1997) and potentiate LTP (Cordoba Montoya and Carrer, 1997) but induce increases in CA1 spine density (Woolley and McEwen, 1992; Woolley et al., 1997). Thus, although the responses to $\mathrm{T}$ and $\mathrm{E}$ appear to be initiated via different receptor systems, the end result for both steroids may reflect intermediary mechanisms involving increases in hippocampal neuronal activity.

Behavioral studies indicate a potential role for $\mathrm{T}$ in maintenance of normal cognitive function in both man and animals. In dogs, orchidectomy has been associated with more rapid cognitive decline in aging (Hart, 2001), although in mice, age-related decrements in cognitive function have been associated with decreased levels of circulating T (Flood et al., 1995). In man, circulating $\mathrm{T}$ concentrations tend to be depressed in men with Alzheimer's disease (Hogervorst et al., 2001), although in normal older men higher bioavailable $\mathrm{T}$ levels are associated with better cognitive performance (Barrett-Connor et al., 1999; Yaffe et al., 2002). Consistent with these observations, short-term $\mathrm{T}$ treatment has been reported to improve verbal and visuospatial memory in healthy older men (Janowsky et al., 2000; Cherrier et al., 2001). Although the mechanisms underlying these observations remain to be established, in females the trophic effects of estrogen on hippocampal structure have been implicated as a potential contributory factor to the enhancement of cognitive performance observed after estrogen replacement (Cordoba Montoya and Carrer, 1997; Luine, 1997). T-mediated remodeling of hippocampal structure might play a comparable role in the behavioral effects of this hormone.

In conclusion, these data indicate that $\mathrm{T}$ is required for maintenance of normal spine synapse density in the CA1 region of the male rat hippocampus. The fact that the effects of $\mathrm{T}$ are not reproduced by administration of $\mathrm{E}$, although they are replicated by administration of the non-aromatizable androgen DHT, strongly suggests that the response to $\mathrm{T}$ is mediated via androgen-specific receptor systems rather than by local conversion of the androgen to estrogen. Androgen-induced changes in hippocampal structure may contribute to the effects of $\mathrm{T}$ on hippocampally mediated behaviors and the regulation of the hypothalamic-pituitaryadrenal axis.

\section{References}

Azcoitia I, Sierra A, Veiga S, Honda S, Harada N, Garcia-Segura LM (2001) Brain aromatase is neuroprotective. J Neurobiol 47:318-329.

Barrett-Connor E, Goodman-Gruen D, Patay B (1999) Endogenous sex hormones and cognitive function in older men. J Clin Endocrinol Metab 84:3681-3685.

Bitran D, Hilvers RJ, Frye CA, Erskine MS (1996) Chronic anabolicandrogenic steroid treatment affects brain $\mathrm{GABA}(\mathrm{A})$ receptor-gated chloride ion transport. Life Sci 58:573-583.

Braendgaar H, Gundersen HJG (1986) The impact of recent stereological advances on quantitative studies of the nervous system. Neurosci Methods 18:39-78.

Brown TJ, Sharma M, Karsan N, Walters MJ, MacLusky NJ (1995) In vitro autoradiographic measurement of gonadal steroid receptors in brain tissue sections. Steroids 60:726-737.

Cherrier MM, Asthana S, Plymate S, Baker L, Matsumoto AM, Peskind E, Raskind MA, Brodkin K, Bremner W, Petrova A, LaTendresse S, Craft S (2001) Testosterone supplementation improves spatial and verbal memory in healthy older men. Neurology 57:80-88.

Clancy AN, Bonsal RW, Michael RP (1992) Immunohistochemical labeling of androgen receptors in the brain of rat and monkey. Life Sci 50:409-417.

Cordoba Montoya DA, Carrer HF (1997) Estrogen facilitates induction of long term potentiation in the hippocampus of awake rats. Brain Res 778:430-438.

Flood JF, Farr SA, Kaiser FE, La RM, Morley JE (1995) Age-related decrease of plasma testosterone in SAMP8 mice: replacement improves age-related impairment of learning and memory. Physiol Behav 57:669-673.

Foy MR, Chiaia NL, Teyler TJ (1984) Reversal of hippocampal sexual dimorphism by gonadal steroid manipulation. Brain Res 321:311-314.

Frye CA, Reed TA (1998) Androgenic neurosteroids: anti-seizure effects in an animal model of epilepsy. Psychoneuroendocrinology 23:385-399.

Frye CA, Park D, Tanaka M, Rosellini R, Svare B (2001) The testosterone metabolite and neurosteroid $3 \alpha$-androstanediol may mediate the effects of testosterone on conditioned place preference. Psychoneuroendocrinology 26:731-750.

Galea LA, Perrot-Sinal TS, Kavaliers M, Ossenkopp KP (1999) Relations of hippocampal volume and dentate gyrus width to gonadal hormone levels in male and female meadow voles. Brain Res 821:383-391.

Gould E, Woolley CS, Frankfurt M, McEwen BS (1990) Gonadal steroids regulate spine synapse density in hippocampal pyramidal cells in adulthood. J Neurosci 10:1286-1291.

Handa RJ, Nunley KM, Lorens SA, Louie JP, McGivern RF, Bollnow MR (1994) Androgen regulation of adrenocorticotropin and corticosterone secretion in the male rat following novelty and foot shock stressors. Physiol Behav 55:117-124.

Harley CW, Malsbury CW, Squires A, Brown RAM (2000) Testosterone decreases CA1 plasticity in vivo in gonadectomized male rats. Hippocampus 10:693-697.

Hart BL (2001) Effect of gonadectomy on subsequent development of agerelated cognitive impairment in dogs. J Am Vet Med Assoc 219:51-56.

Hogervorst E, Williams J, Budge M, Barnetson L, Combrinck M, Smith AD (2001) Serum total testosterone is lower in men with Alzheimer's disease. Neuroendocrinol Lett 22:163-168.

Isgor C, Sengelaub DR (1998) Prenatal gonadal steroids affect adult spatial behavior, CA1 and CA3 pyramidal cell morphology in rats. Horm Behav 34:183-198.

Janowsky JS, Chavez B, Orwoll E (2000) Sex steroids modify working memory. J Cognit Neurosci 12:407-414.

Kerr JE, Allore RJ, Beck SG, Handa RJ (1995) Distribution and hormonal regulation of androgen receptor $(A R)$ and $A R$ messenger ribonucleic acid in the rat hippocampus. Endocrinology 136:3213-3221.

Leranth C, Shanabrough M (2001) Supramammillary area mediates subcortical estrogenic action on hippocampal synaptic plasticity. Exp Neurol 167:445-450.

Leranth C, Shanabrough M, Horvath TL (2000) Hormonal regulation of 
hippocampal spine synapse density involves subcortical mediation. Neuroscience 101:349-356.

Leranth C, Shanabrough M, Redmond Jr DE (2002) Gonadal hormones are responsible for maintaining the integrity of spine synapses in the CA1 hippocampal subfield of female non-human primates. J Comp Neurol 447:34-42.

Lewis C, McEwen BS, Frankfurt M (1995) Estrogen-induction of dendritic spines in ventromedial hypothalamus and hippocampus: effects of neonatal blockade and adult GDX. Devl Brain Res 87:91-95.

Lieberburg I, McEwen BS (1977) Brain cell nuclear retention of testosterone metabolites, $5 \alpha$-dihydrotestosterone and estradiol- $17 \beta$ in adult rats. Endocrinology 100:588-597.

Luine VN (1997) Steroid hormone modulation of hippocampal dependent spatial memory. Stress 2:21-36.

MacLusky NJ, Walters MJ, Clark AS, Toran-Allerand CD (1994) Aromatase in the cerebral cortex, hippocampus, and mid-brain: ontogeny and developmental implications. Mol Cell Neurosci 5:691-698.

Meyer G, Ferres-Torres R, Mas M (1978) The effects of puberty and castration on hippocampal dendritic spines of mice. A Golgi study. Brain Res 155:108-112.

Patchev VK, Almeida OF (1996) Gonadal steroids exert facilitating and "buffering" effects on glucocorticoid-mediated transcriptional regulation of corticotropin-releasing hormone and corticosteroid receptor genes in rat brain. J Neurosci 16:7077-7084.

Pike CJ (2001) Testosterone attenuates beta-amyloid toxicity in cultured hippocampal neurons. Brain Res 919:160-165.

Roof RL, Havens MD (1992) Testosterone improves maze performance and induces development of a male hippocampus in females. Brain Res 572:310-313.

Rusakov DA, Davies HA, Harrison E, Diana G, Richter-Levin G, Bliss TVP, Stewart MG (1997) Ultrastructural synaptic correlates of spatial learning in rat hippocampus. Neuroscience 80:69-77.

Sakata K, Tokue A, Kawai N (2000) Altered synaptic transmission in the hippocampus of the castrated male mouse is reversed by testosterone replacement. J Urol 163:1333-1338.

Shors TJ, Chua C, Falduto J (2001) Sex differences and opposite effects of stress on dendritic spine density in the male versus female hippocampus. J Neurosci 21:6292-6297.

Simerly RB, Chang C, Muramatsu M, Swanson LW (1990) Distribution of androgen and estrogen receptor mRNA-containing cells in the rat brain: and in situ hybridization study. J Comp Neurol 294:76-95.

Small JV (1968) Measurement of section thickness. In: Proceedings of the European Conference on Electron Microscopy, pp 609-610. Rome: Tipographia Poliglotta Vatican.

Smith MD, Jones LS, Wilson MA (2002) Sex differences in hippocampal slice excitability: role of testosterone. Neuroscience 109:517-530.

Sterio DC (1984) The unbiased estimation of number and sizes of arbitrary particles using the disector. J Microsc 134:127-136.

Tabibnia G, Cooke BM, Breedlove SM (1999) Sex difference and laterality in the volume of mouse dentate gyrus granule cell layer. Brain Res 827:41-45.

Wong M, Moss RL (1992) Long-term and short-term electrophysiological effects of estrogen on the synaptic properties of hippocampal CA1 neurons. J Neurosci 12:3217-3225.

Woolley CS, McEwen BS (1992) Estradiol mediates fluctuation in hippocampal synapse density during the estrous cycle in the adult rat. J Neurosci 12:2549-2554.

Woolley CS, Gould E, Frankfurt M, McEwen BS (1990) Naturally occurring fluctuation in dendritic spine density on adult hippocampal pyramidal neurons. J Neurosci 10:4035-4039.

Woolley CS, Weiland NG, McEwen BS, Schwartzkroin PA (1997) Estradiol increases the sensitivity of hippocampal CA1 pyramidal cells to NMDA receptor-mediated synaptic input: correlation with dendritic spine density. J Neurosci 17:1848-1859.

Yaffe K, Lui LY, Zmuda J, Cauley J (2002) Sex hormones and cognitive function in older men. J Am Geriatr Soc 50:707-712. 